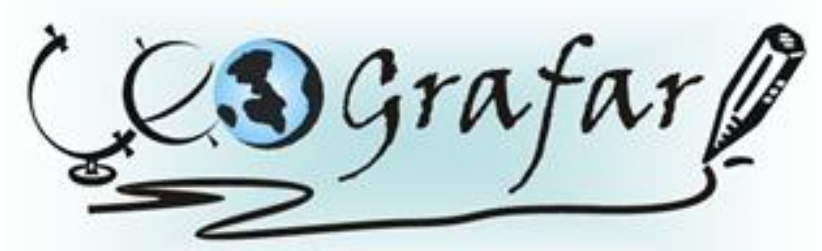

Revista Eletrônica do Programa de Pós-Graduaçāo em Geografla - UFPR

\title{
O PROCESSO DE DES(RE)TERRITORIALIZAÇÃO DOS TRABALHADORES NORDESTINOS NO TERRITÓRIO AMAZÔNICO DURANTE OS CICLOS DA BORRACHA
}

\author{
ADNILSON DE ALMEIDA SILVA ${ }^{1}$ \\ ANTÔNIO CARLOS GALVÃO DA SILVA ${ }^{2}$ \\ JANIA MARIA DE PAULA ${ }^{3}$ \\ JOSUÉ DA COSTA SILVA ${ }^{4}$ \\ LUCILEYDE FEITOSA SOUSA ${ }^{5}$
}

\begin{abstract}
Resumo: O artigo apresenta os resultados de pesquisa do Grupo de Estudos e Pesquisas Modos de Vida e Culturas Amazônica (GEPCULTURA/UNIR) sobre as implicações da des (re) territorialização nos seringais da Amazônia, atendo-se aos Ciclos da Borracha, no período compreendido entre o século XIX e meados da década de 1960. O objetivo consistiu em analisar o processo de dês (re)territorialização dos nordestinos (Batalha da Borracha), no território amazônico. Buscou-se uma abordagem geográfica, sobretudo, com base na contribuição de Santos (2006), Costa (2004) e pesquisadores da própria região amazônica: Amaral (2004), Almeida Silva (2007), Benchimol (1992), Ferrarini (1976; 1979), Nascimento Silva (2000), Paula (2008), Silva (1994) E Silva (2008), para melhor reflexão dessa nova configuração do espaço amazônico. Entender tal processo passa pela compreensão dos fatores e políticas públicas governamentais adotadas no período dos Ciclos da Borracha (Séculos XIX e XX), os quais atraíram nordestinos ávidos por melhores condições de vida, colaborando para a reconstrução de um novo território, o qual não se restringiu a simples demarcação de limites físicos, mas a um espaço dinâmico no interior da Amazônia, propiciando o surgimento de uma cultura que, juntamente com a cultura local e de caráter fortemente indígena, se fundiu enriquecendo mais esse território amazônico.
\end{abstract}

Palavras-Chave: Amazônia. Cultura. Des(re)territorialização. Território. Seringueiros.

\section{PROCESS OF NOTHEASTERN WORKERS'S DIS (RE) TERRITORIALIZATION IN THE AMAZON TERRITORY DURING THE CYCLE OF RUBBER}

\footnotetext{
${ }^{1}$ Mestre em Geografia pela Universidade Federal de Rondônia - UNIR. Doutor em Geografia pela Universidade Federal do Paraná - UFPR e pesquisador-colaborador do Núcleo de Estudos em Espaços e Representações - NEER e do Grupo de Estudos e Pesquisas sobre Modos de Vida e Populações Amazônicas - GEP Cultura Amazônica/UNIR. E-mail: adnilsonn@hotmail.com

${ }^{2}$ Mestre em Geografia pela UNIR e pesquisador do Grupo de Estudos e Pesquisas sobre Modos de Vida e Populações Amazônicas - GEPCultura Amazônica/UNIR. E-mail: acgalvao@globo.com

${ }^{3}$ Mestre em Geografia pela Universidade Federal de Rondônia - UNIR e docente-colaboradora do Departamento de Geografia da UNIR. E-mail: jania.maria@hotmail.com

${ }^{4}$ Professor do Departamento de Geografia e do Programa de Pós-Graduação Mestrado em Geografia - UNIR. Pesquisador do GEPCULTURA e NEER. E-mail: jcosta@unir.br

${ }^{5}$ Mestra em Desenvolvimento Regional pela UNIR. Doutoranda em Geografia UFPR e pesquisadoracolaboradora do NEER e GEP Cultura Amazônica/UNIR. Bolsista do PROCAD-AMAZÔNIA/CAPES. E-mail: lucileyde@feitosa.org
} 


\begin{abstract}
This paper presents research results of the Study and Research life styles and Amazon Cultures (GEPCULTURA / UNIR) on the implications of dis (re) territorialization in the rubber of the Amazon. It considers the rubber period, the period from the nineteenth century and the mid-1960. The objective was to analyze the process of dis (re) territorialization of the Northeastern (The rubber battle) in the Amazon territory. The research tried to identify a geographical approach, mainly based on the contribution of SANTOS (2006), COSTA (2004) and researchers of this region: AMARAL (2004), ALMEIDA SILVA (2007), BENCHIMOL (1992), FERRARINI (1976; 1979), NASCIMENTO SILVA (2000), PAULA (2008), SILVA (1994) and SILVA (2008), for a better reflection of this new design of the Amazon space. Understanding this process requires the understanding of the factors and government policies adopted in the period of the Cycles of Rubber (in the centuries XIX and XX), which attracted eager Northeastern for better conditions of life, helping to rebuild a new territory, which is not restricted the simple demarcation of physical boundaries, but a dynamic area in the Amazon region, facilitating the emergence of a culture which, together with the local culture and strongly indigenous character, merged further enriching the Amazon territory.
\end{abstract}

Key Words: Amazon. Culture. Dis (re) territorialization. Tappers. Territory.

\title{
INTRODUÇÃO
}

Entender a complexidade da territorialidade amazônica exige uma reflexão dos processos histórico-geográficos que a constituíram, sendo essa região um palco de lutas, de encontros, desencontros, contradições, esperanças e desventuras. As marcas desses processos estão presentes, cristalizadas ou na afirmação de Santos (2006) apresentam-se repletas de rugosidades que incorporam o antigo e o atual, explicando não somente a dinamicidade territorial, mas ainda as imensas desigualdades regionais.

A análise do processo de des(re)territorialização dos nordestinos (Batalha da Borracha), no espaço territorial amazônico, é portadora de grandes representações e significados, porque decorre de uma série de transformações culturais, sociais, políticas, ambientais e econômicas cristalizadas na região, verificadas desde os meados do Século XIX aos dias atuais e permite entendê-la como uma ação geopolítica em assegurar o território e a territorialidade brasileira.

Nesta compreensão, o método de trabalho realizado por nós consiste na abordagem geográfica, a partir de referenciais teórico-bibliográficos com autores consagrados e outros estudiosos sobre as temáticas do território, territorialidade e Amazônia, tendo como preocupação o entendimento relativo à configuração territorial amazônica, assim como ao processo de des(re)territorialização do povo nordestino nesta porção territorial brasileira.

Os resultados das reflexões sobre como o processo de des(re)territorialização procura demonstrar as profundas marcas produzidas, sejam sociais, econômicas, 
políticas, culturais e ambientais, que são sentidas na configuração territorial amazônica, especialmente em municípios mais isolados da região, como é o caso de Lábrea, cuja visibilidade dos Ciclos da Borracha, ainda é perceptível.

\section{AMAZÔNIA: CENÁRIO E PALCO DAS CONSTRUÇÕES DAS TERRITORIALIDADES}

A Amazônia brasileira desde tempos imemoriais foi habitada ancestralmente pelas populações indígenas que aqui desenvolviam um modo de vida muito peculiar e imprimiram suas marcas no território, através de uma cultura sui generis, que ainda nos dias atuais se presentifica fortemente como representação, apesar das intensas tentativas de descaracterização de suas identidades.

Durante quatro séculos, após a chegada do homem não-indígena ao Brasil, essas populações viveram na região Amazônia praticamente sem pressões que pudessem levá-los a um processo de transformação de suas culturas, todavia tal situação foi alterada com a expansão do sistema capitalista, com a conquista e a formação de fronteiras geopolíticas como atributo da modernidade e o advento do Estado-Nação.

O Estado brasileiro passou a destinar maior atenção a Amazônia somente após a segunda metade do século XIX, devido a dois importantes fatores sócioeconômico e político: a) quando a economia do país começou a sofrer com a crise instalada na produção cafeeira; b) quando os ingleses descobriram o processo de vulcanização da borracha. Esses fatores colaboraram para que ocorressem a transformação da borracha amazônica como um dos produtos de sustentáculo da economia brasileira, especialmente no período em que ocorre a II Guerra Mundial.

A fim de consolidar o processo de exploração da borracha foram necessárias medidas de caráter político-administrativas e estratégicas por parte do Governo Federal. Neste sentido, incentivou-se amplamente a vinda de nordestinos para a região com o intuito de suprir a necessidade de mão-de-obra.

Nos anos de 1877-1879, no contexto das secas que castigavam o nordeste brasileiro, os migrantes daquela região, principalmente os do estado do Ceará, deram à Amazônia outra configuração territorial. Muito mais que flagelados pelas 
longas estiagens daquela região, os nordestinos eram incentivados pelo Governo Federal a se transferirem para a Amazônia, também como forma de amenizar os conflitos sociais provenientes da concentração fundiária lá instalada desde o período colonial.

Essa lógica, revela que "uma sociedade rural em que um pequeno grupo detinha o controle da terra e explorava a grande maioria da população, exercendo sobre a mesma um forte controle, não poderia ser uma sociedade calma, pacífica e tranqüila" (ANDRADE, 2000, p. 18).

Nem as grandes dificuldades encontradas no inóspito território amazônico conseguiram limitar o crescente avanço de reterritorialização na "mata virgem". A estimativa era que, desde o início do ciclo da borracha até os anos sessenta do século XX, aproximadamente 500.000 nordestinos que vieram tentar a vida na Amazônia, conforme afirmam Dean (1989), Nascimento Silva, 2000; Silva, 2008).

Discorrer sobre a diáspora nordestina, no período áureo da borracha e da miséria no sertão do nordeste, requer cuidado e a percepção de que o território não se restringe a demarcação ou porção de determinado espaço, limites físicos, matéria puramente concreta, mas ao espaço entendido, constituído e representado pela essência daqueles que lhe deram formação.

O processo de des(re)territorialização vivenciado por milhares de nordestinos que, mesmo sentindo o flagelo da seca e a opressão do sistema capitalista, mediante a desumanidade e ganância dos seringalistas, moldaram a nova vida no seio de uma terra desconhecida. Contudo, essa nova territorialização não levou esses retirantes a se despirem do mundo vivido de suas raízes. Trouxeram seus costumes e um modo de vida que se fundiu com a cultura local, fortalecendo essa nova territorialização.

\section{CONTEXTUALIZAÇÃO DOS CONCEITOS}

De início, a concepção de território é tratada, do ponto de vista conceitual, por muitos autores de forma não linear. Deste modo, entender a des(re)territorialização de um grupo e as concepções que emergem, é uma forma de vislumbrar um melhor 
entendimento do objeto do qual nos propusemos a analisar. Assim, é de fundamental importância que se busque, de modo sucinto, uma breve explanação do entendimento dos conceitos de território, desterritorialização e reterritorialização.

Quando se ouve alguém falar de território, é natural que logo associemos esta palavra como sendo a extensão de terra ou área pertencente a um país, estado, município, cidade ou vila. De imediato, não nos damos conta que esse espaço formador do território carrega toda uma história, representações, percepções e modos de vida. No entanto, dificilmente temos a capacidade necessária para perceber que o território é movido por forças que o constituem e que a cada momento transformam este espaço num território com características diferentes das existentes anteriormente.

Neste aspecto, apropriamo-nos do conceito de território usado para a compreensão do contexto amazônico e sua relação com a "formação" de uma nova identidade na região.

O território não é apenas o conjunto dos sistemas naturais e de sistemas de coisas superpostas; o território tem que ser entendido como o território usado, não o território em si. O território usado é o chão mais a identidade. $A$ identidade é o sentimento de pertencer àquilo que nos pertence. $O$ território é o fundamento do trabalho; o lugar da residência, das trocas materiais e espirituais e do exercício da vida. (SANTOS, 2006, p. 140).

Nas palavras de Santos, o território não se restringe à demarcação ou à porção de determinado espaço, aos limites físicos, mas ao espaço de especificidades e peculiaridades, deve ser entendido como um todo, apreendido como elemento vivo, dinâmico, dialético, representando tudo que nele existe.

Argumento semelhante é compartilhado por Costa (2004, p.50), ao considerar que os "territórios são ao mesmo tempo, agentes causadores de desterritorialização e reterritorialização", uma vez que, esse território deve ser percebido e entendido não meramente como uma coisa ou objeto, mas sim, como "um ato, uma ação" e que "o território reforça sua dimensão enquanto representação, valor simbólico".

Ainda, explanando sobre a desterritorialização, Deleuze e Guattari apud Costa (2004, p.127) argumentam que: "a desterritorialização é o movimento pelo qual se 
abandona o território, "é a operação da linha de fuga", e a reterritorialização é o movimento de construção do território".

Destarte, constata-se que é no território onde se efetiva o grande palco de lutas, contradições, permitindo sua construção, desconstrução e reconstrução, dentro de uma temporalidade específica e a vivência de cada momento histórico:

[...] A compreensão da territorialidade, do tempo e das ações humanas que se desencadeiam sobre os mesmos assumem conotações e posições diferenciadas de entendimento nos diversos momentos de toda a história humana. É necessário compreender que tanto a territorialidade quanto a temporalidade são hierarquias concebidas pela própria condição humana, e como tal seguem a lógica igualmente humana de apropriação e uso daquilo que fazemos e construímos.

[...] A territorialidade como é apresentada, se coloca como elemento de expressão e sustentação, implicando na formação social, política e econômica, provocando, por sua vez uma diferenciação e dissociação entre as pessoas e os lugares, o ser, o estar e o fazer, exprimindo e ditando a lógica do comportamento da sociedade. (ALMEIDA SILVA, 2007, p. 13).

Como observamos, para que exista território é necessária uma ação de construção, a qual é produzida por seus diversos e distintos atores. Logo, a territorialidade está ligada a uma ação e ultrapassa o território. Assim, os nordestinos que para a Amazônia vieram não perderam a essência de sua territorialidade anterior que, aos poucos e frente às novas realidades, adquiriram uma territorialização construída, a partir de novos modos de vida. É com esta vivência que se adquire uma nova identidade, conseqüentemente uma nova territorialização e configuração territorial.

Podemos dizer que as secas que atingiram o nordeste em certos períodos, causando uma verdadeira diáspora de partes desse território, podem ser consideradas como "desterritorialização natural”. Nesta perspectiva,

[...] em certo sentido, podemos até mesmo afirmar que também existe uma espécie de "desterritorialização natural" da sociedade, na medida em que fenômenos naturais como vulcanismos e terremotos são responsáveis por mudanças radicais na organização de muitos territórios [...]( COSTA, 2006, p. 48). 
Neste ponto, de acordo com o apontado até então, podemos dizer que toda construção de território nos transmite a idéia de desterritorialização e, conseqüentemente, reterritorialização. Logo, o território expressa nitidamente as contradições sócioespaciais, em decorrência da inserção e dinâmica que o Capital impõe sobre o espaço.

Assim, a reterritorialização também é um processo advindo do próprio território; sendo que a reterritorialização é justamente o reencontro, é o movimento de construção de um novo território. É a nova configuração, o conjunto de artifício pelos quais um elemento anteriormente desterritorializado dá territorialidade nova a seu espaço de ocupação, territorialidade esta que não só lhe permite, de acordo com Gallois (2004, p.37) em "recuperar e valorizar a história da ocupação de sua atual terra, como propicia a melhor compreensão dos elementos culturais nas redes de experiências desta ocupação".

Aqui, é perceptível como os projetos governamentais trazem em seu bojo o processo de desterritorialização e reterritorialização, a exemplo dos jovens convocados a servirem à Pátria, na condição de extratores de borracha, no período da Segunda Guerra Mundial, na Amazônia.

O processo de des(re)territorialização na Amazônia pode ser entendido como incompleto, principalmente por se tratar ainda de uma região considerada como a última grande fronteira do Planeta a ser explorada. Esse processo, na Amazônia brasileira é historicamente anterior ao surgimento da própria nação, conforme o argumento a seguir:

Registros mostram que a exploração da Amazônia brasileira teve início há pelo menos quatro séculos. Contudo, sua ocupação efetivamente tomou força na segunda metade da década de setenta do século dezenove, motivada pela procura da exploração do látex. Desde então, por muitos anos, esse tipo de atividade proporcionou à região uma nova configuração em seu espaço. Durante o apogeu desse processo extrativista, cidades foram erguidas e ostentavam grandes riquezas, aonde, boa parte das pessoas que nelas viviam levava uma vida regada de muito requinte. Entrementes, os que verdadeiramente proporcionavam esses momentos de glamour, eram submetidos a um modo de vida no seringal que em nada se assemelhava aos vivenciados nas cidades (SILVA, 2008, p. 23). 


\section{DA SEGUNDA GUERRA MUNDIAL À BORRACHA NA AMAZÔNIA: O CONTEXTO DAS POLÍTICAS PÚBLICAS}

A ocupação da Amazônia por não-indígenas ocorreu inicialmente de forma tímida, todavia adquire nova dinamicidade a partir da introdução do processo de vulcanização - borracha estabilizada quimicamente com a mistura de enxofre em presença de calor - em 1839, por Charles Goodyear, resultando na procura de matéria-prima que permitiu a efetiva penetração e conquista da Floresta Amazônica, consequentemente resultando em inúmeros conflitos com as populações indígenas.

Com a abertura da Amazônia ao comércio exterior, na década de 1850, a política então desenvolvida pelo Governo Brasileiro continuou a se mostrar de dependência econômica estrangeira, permitindo a exploração da borracha ao capital internacional. Neste sentido, afirma Dean (1989, p. 34):

\footnotetext{
O Brasil abriu a Amazônia ao comércio exterior nos anos de 1859, permitindo a operação de uma companhia britânica de navegação. Nesse período a exploração científica realizou-se sob licença do governo, o qual, embora com justificados motivos de apreensão quanto às intenções dos estrangeiros.
}

A crescente demanda de borracha estava mudando rapidamente os recursos regionais, estimava-se que cerca de vinte e cinco mil pessoas se dedicavam à coleta da borracha, sobretudo nos arredores da cidade de Belém. Em nenhum momento houve preocupação por parte do Governo brasileiro com as transformações das quais atingiam as populações locais, naquela época composta por uma enorme sociodiversidade indígena, além de caboclos. Para intensificar a exploração da borracha, a solução era a adoção de políticas migratórias.

Por sua vez, o objetivo de conquista da Amazônia era o de "suprir a falta de mão-de-obra nos seringais, o que levou o Governo a provocar um grande movimento migratório com populações provenientes da Região Nordeste" (SILVA, 1994, p. 25). Assim, o processo de avanço capitalista na região resolvia vários problemas regionais: disponibilidade de mão-de-obra para os seringais amazônicos e contenção dos conflitos sociais existentes no Nordeste em virtude da concentração latifundiárias e as estiagens prolongadas, e em contrapartida disponibilizava a oferta 
de matéria-prima para atender ao mercado internacional, particularmente à indústria automobilística que ora se iniciava.

Nos seringais amazônicos, além da presença do migrante nordestino, Ribeiro (2000) registra a ocorrência da destribalização de grupos indígenas para atuarem no corte da borracha, o que provocou além de um velado processo de escravidão, a dizimação de inúmeros grupos ${ }^{6}$ em virtude de doenças transmitidas pelo contato com o não-indígena.

A diáspora e o conseqüente processo de des(re)territorialização vivenciado por milhares de nordestinos que, mesmo sentindo o flagelo da seca e a opressão do sistema capitalista, em decorrência da barbárie e ambição dos seringalistas ${ }^{7}$, acomodaram a nova vida no interior de uma terra estranha. Contudo, essa nova territorialização não levou esses migrantes a abandonarem os valores do mundo vivido de suas raízes originais.

A nova realidade é emblemática e peculiar, auxilia na compreensão do modo de vida amazônico na atualidade, visto que os nordestinos trouxeram seus costumes e um modo de vida que se amalgamou com a cultura local, posteriormente fortaleceu a compreensão de nossas territorialidades, podendo ser feito uma aproximação de análise como a realizada por Paula (2008, p. 67):

A busca pela perpetuação das heranças sócio-territoriais (a tradição, a cultura própria e a organização espacial) [...] faz aflorar o desejo de manifestação das identidades culturais em populações minoritárias que lutam pelo seu reconhecimento frente à sociedade que o envolve.

Nesse aspecto de enraizamento, o que constatamos é um processo de afirmação do grupo frente à nova realidade, aos novos desafios e estratégias de

\footnotetext{
${ }^{6} \mathrm{Na}$ Amazônia como um todo, esse enfrentamento real vitimou inúmeras populações indígenas. Exemplo disso ocorreu em Rondônia, entre tantos grupos destribalizados por conta do trabalho no seringal, os indígenas Arara (Karo do grupo Tupi Rama-Rama), além de trabalharem como escravos nos seringais foram desterritorializados. Somente após a década de 1960 foram realdeados, tendo garantido parte de seu território original, em razão da ocupação pelos Gavião (Ikólóéhj do grupo TupiMondé), dos quais eram inimigos ancestrais. Hoje, esses dois vivem em relativa harmonia na Terra Indígena Igarapé Lurdes.

${ }^{7}$ Seringalistas são os proprietários de seringais, detentores da terra a ser explorada e do capital; os seringueiros são trabalhadores que extraíam o látex e indubitavelmente eram obrigados a defender os seringais, assim eram "soldados" de uma guerra que não Ihes pertencia, mas que não podiam dela se omitir.
} 
sobrevivência, mesmo isso representando fortes resistências que ainda persiste na atualidade, em razão do não-reconhecimento dessas valiosas pessoas por parte da sociedade.

Após a invasão alemã à Holanda e França, o mundo viu-se temeroso quanto ao futuro das colônias produtoras de seringais cultivados no sudeste asiático. A partir de então foram criadas, pelos Estados Unidos, medidas que pudessem assegurar o fornecimento de borracha, uma vez que este país, segundo Dean (1989, p.131) consumia em torno de 50.000 toneladas por mês a um custo muito acima do normal.

Assim, na década de 1942, com o objetivo de impulsionar a produção de borracha, o Estado brasileiro firmou convênio com a empresa norte-americana Rubber Reserve Company - RCC, mudando o nome mais tarde para Rubber Development Corporation (RDC) e definindo o que se convencionou periodizar como o segundo ciclo da borracha.

A estratégia geopolítica adotada na região Amazônia permitiu a celebração de vários compromissos assumidos pelo Brasil, por ocasião da assinatura do Acordo de Washington, cujo objetivo era a venda exclusiva de toda a produção de borracha excedente às necessidades internas do Governo Norte-Americano, cujo acordo vigoraria. Sobre esta questão, Dean (1989, p.139) destaca que durante "um período de cinco anos a um preço mínimo, fixado inicialmente em 39 centavos de dólar a libra-peso para entregar acima de 10.000 toneladas". Em contrapartida, o Brasil tinha garantias de receber assistência financeira e material que objetivavam proporcionar a infra-estrutura necessária à expansão do comércio da borracha.

O referido acordo, celebrado no Governo de Getúlio Vargas, conforme Oliveira (1991) dentre outras medidas instituíram o monopólio estatal da borracha através da criação do Banco da Amazônia, mas com uma curiosa participação de $50 \%$ de capital norte americano. Em virtude da inserção e avanço do Capital nos seringais, fez com que ocorressem inúmeros conflitos envolvendo seringueiros e indígenas, provocando mortes, além das expedições punitivas aos povos indígenas, a exemplo do que fizeram o seringalista Manoel Lucindo, entre outros, conforme asseguram Leonel (1995) e Vilaça (2006), respectivamente nas obras Etnodicéia Uru-Eu-Wau- 
Wau e Quem Somos Nós: os Wari encontram os brancos, as quais tratam de genocídios praticados contra os Kawahib (Jupaú e Amondawa) e Wari̊.

Em busca de viabilizar a extração do látex foram criados, tanto pelo governo brasileiro como pelo norte-americano, órgãos e instituições incumbidas de fazerem não só o financiamento, mas também, todo o processo seletivo, logístico e sanitário; contudo, os dirigentes desses órgãos nem sempre cumpriam de maneira satisfatória a competência designada. Nascimento Silva (2000, p.51) destaca a criação das seguintes instituições com intuito de fomentar a extração da borracha:

- Banco de Crédito da Borracha - BCB, encarregado de realizar operações de crédito, fomentar a produção, financiar a empresa extrativista, bem como exercer o monopólio final da compra e venda da borracha, tanto interna quanto externa, criado através do Decreto-lei no 4.841 , de 17 de outubro de 1945;

- Departamento Nacional de Imigração - DNI, tinha como finalidade recrutar e encaminhar trabalhadores para a Amazônia, como também fiscalizar outros órgãos envolvidos na mobilização;

- Comissão de Controle dos Acordos de Washington - CCAW, coordenando e auxiliando as atividades de grupos brasileiros e estadunidenses que atuariam na operação da "batalha da borracha", criada através do Decretolei no 4.523, de 25 de julho de 1942;

- Superintendência para o Abastecimento do Vale Amazônico - SAVA, com a finalidade abastecer com gêneros alimentícios o Vale Amazônico, e ainda coordenar as medidas a serem tomadas com o Estado da região visando o abastecimento e incremento da produção de alimentos, providenciando a aquisição das mercadorias, dentro e fora do país, e seu transporte para a Amazônia, formando estoques, criada através do Decreto-lei nํ⒌044, de 04 de dezembro de 1942;

- Serviço Especial de Mobilização de Trabalhadores para a Amazônia SEMTA, depois substituído pela Comissão Administrativa de Encaminhamento de Trabalhadores para Amazônia - CAETA, cujo objetivo era recrutar, encaminhar e colocar trabalhadores nos seringais, transportando-os até Belém;

- Serviço Especial de Saúde Pública - SESP, encarregado de prestar assistência médica e sanitária aos "soldados da borracha";

- Serviço de Navegação e Administração do Porto do Pará - SNAPP, encarregado de transportar os "soldados da borracha" dos portos de Belém para Manaus, Porto Velho e Acre.

Nesse processo de mobilização de trabalhadores para a Amazônia, o Departamento Nacional de Imigração (DNI) e a Rubber Development Corporation (RDC), somente no final de 1942 e início de 1943, conseguiram trazer para a Amazônia cerca de 15.000 pessoas, de acordo com Nascimento Silva (2000, p.52).

\footnotetext{
${ }^{8}$ Os Wari, pertencem ao tronco lingüístico txapakura, e também são conhecidos como Pakaanóva.
} 
Com o término da guerra, a expectativa daqueles que, de alguma forma, estavam ligados ao comércio da borracha era intensa, todavia, não eram merecedoras de uma perspectiva otimista, pois, a maioria tinha a concepção de que em pouco tempo o comércio da borracha silvestre do Brasil não mais se manteria no mercado mundial. Apenas um ingrediente contribuía para que esse fato não se concretizasse de imediato, estando condicionado ao fato de que os acordos firmados com os Estados Unidos previam a garantia de vendas da borracha brasileira até junho de 1947 , ao dobro do preço praticado no mercado mundial. O que percebemos foi o crescimento da demanda de forma significativa da borracha no mercado interno, fruto da expansão de empresas fabricantes de pneus e instaladas no país, logo após o início da guerra.

Paradoxalmente, em vez da produção da borracha acompanhar o aumento da demanda de pneus, o que ocorreu foi a redução acentuada de sua produção chegando, segundo Dean (1989, p.164), a despencar de "32.930 toneladas em 1947 para 18.619 em 1950". Esse quadro fez com que o Governo do Brasil autorizasse a importação de quatrocentas toneladas de borracha, advindas do sudeste asiático, com afirma o mencionado autor, fato este que desencadeou, por parte da imprensa e autoridades, muitos protestos, levando o governo brasileiro a adotar novas medidas para fins de impulsionar a produção gomífera a fim de suprir às necessidades internas.

Nesse período, o Banco de Crédito da Borracha passou a chamar-se Banco de Crédito da Amazônia, atendo-se aos interesses de empresários extratores, destinando quase toda sua totalidade de recursos para o financiamento da borracha na Amazônia. Em 1953, por influência de Felisberto Camargo, diretor do Instituto Agronômico do Norte, foi proposto e criado o Fundo de Desenvolvimento do Amazonas e a Superintendência do Plano de Valorização Econômica da Amazônia SPVEA que, diante de sua ineficiência, foi substituído pela Superintendência de Desenvolvimento da Amazônia - SUDAM, com o objetivo de supervisionar um programa de incentivos fiscais para novos investimentos na região. O Banco de Crédito da Amazônia foi transformado no atual Banco da Amazônia - BASA.

Ainda criou-se a Superintendência de Desenvolvimento da Borracha SUDHEVEA, através da Lei no. 5.227, de 18 de janeiro de 1967, para gerenciar o 
estoque estratégico do produto, realizar estudos de mercado e rever os planos governamentais e particulares para o desenvolvimento da borracha, além de agilizar a política de racionalização do setor da borracha.

\section{DESTERRITORIALIZAÇÃO DO HOMEM NORDESTINO}

As grandes secas no nordeste forçaram milhares de pessoas a abandonar sua região; muitos deixaram familiares por conta do sonho de ganhar dinheiro na extração do látex. Com a chegada na Amazônia, viram a árdua batalha para continuarem a lutar pela sobrevivência. Ferrarini, ao descrever a transmigração dos nordestinos para a Amazônia, mostra a seca como fator preponderante, a qual influenciou na desterritorialização do Nordeste e na reterritorialização de boa parte da Amazônia. Esse movimento migratório ocorreu devido:

a) Guerra. No período das guerras mundiais, sendo a borracha um produto essencial, estimulou o governo a vinda de nordestinos para, deste modo, atender a demanda bélica e abastecer o mercado interno.

b) Obrigação. Outros foram obrigados a partir para a Amazônia Ocidental, caso contrário teriam de ir para os campos da Europa. Deste modo muitos se tornaram "soldados da borracha".

c) Enfim outros simplesmente estavam à procura de aventura, dinheiro, vida fácil [...]. (FERRARINI, 1979, p. 44).

Vários foram os períodos de seca nos estados nordestinos ao logo dos séculos XVIII e XIX, os quais arrasaram plantações, dizimaram animais e expulsaram a população. Benchimol (1992, p. 186), citando Tomaz Pompeu de Souza Brasil, observa que "na grande seca de 1877, somente no mês de novembro, os retirantes foram 42.931 e em dezembro desse mesmo ano, 83.000. Em 1878, os flagelados atingiram 108.656". Em seguida, Benchimol (1992, p.187), na mesma obra referencia a contribuição de Rodolfo Teóphilo, argumentando que "O Ceará perdeu em 1878, por mortes, 118.927 e, pela imigração, 54.875, ou o total de 173.802 pessoas".

Nesse contexto, dois fatos contribuem para a diáspora nordestina rumo à Amazônia: a violenta seca de 1877 no Nordeste brasileiro, e o término da Guerra da Secessão (1864-1868) nos Estados Unidos possibilitando aquele país voltar a 
produzir algodão para consumo próprio, desmobilizando grande quantidade de mãode-obra nordestina anteriormente ocupada na cultura do produto, principalmente no Ceará. Assim além da seca, a queda na lucratividade da produção algodoeira no Nordeste contribuiu para a expulsão desses trabalhadores, direcionando-os à Amazônia.

As principais motivações da vinda do nordestino, principalmente do Ceará, para a Amazônia se deu em busca de melhor condição de vida, motivada pelas secas que castigavam aquela região e posteriormente pela Segunda Guerra Mundial. O deslocamento do cearense para a Amazônia é retratado como uma necessidade e revela uma dura realidade frente ao desconhecido e o sentimento de "ponto de fuga", como uma busca de algo que possibilitava o encontro de uma vida melhor:

\begin{abstract}
Estava no Ceará com minha família. Era soldado. O chefe, por causa da guerra, pediu que muitos viessem para o Amazonas extrair o leite do lacre. Era solteiro; não tinha o que deixar. Vim acompanhado de mais de mil homens para esse trabalho. Embarquei no navio Manauense. Eu e meus companheiros fomos divididos em equipes. Duas ou três equipes extraíam o leite do lacre e outros da seringueira. Senti falta somente da minha família que ficou longe, e que nunca mais vi. Tenho lá a família, minha terra natal onde vivi tantos anos. A vida no nordeste é melhor. Além de estar com minha família e parentes, lá está toda a minha juventude. Não vim ao Amazonas cortar seringa, não. Vim fugido da guerra e da seca que teve lá e que sofri muito, bem como toda a minha família. (FERRARINI, 1979, p.44),
\end{abstract}

O relato do soldado da borracha mostra a carga de sentimentos e de emoções, o novo modo de vida que the foi imposto, não perdendo sua essência e seus laços afetivos com a família e com a terra, ou seja, não perdeu sua territorialização com o lugar de origem.

A geopolítica adotada à época para a Amazônia levou, segundo Dean (1989, p.151), de acordo com levantamento feito pelo "Congresso Constituinte Federal, convocado após a queda da ditadura Vargas", a uma estimativa de que entre dezessete a vinte mil pessoas das que se dispuseram à luta da borracha jamais retornaram a seus locais de origem - "perda maior do que a sofrida pela Força Expedicionária Brasileira na Itália".

Outra questão igualmente intrigante diz respeito aos jovens que desde cedo trabalhavam nos seringais, dando sua vida pela Nação, e sequer são reconhecidos 
como "soldados da borracha", em virtude da legislação aplicada, sendo hoje duplamente prejudicados por não serem considerados trabalhadores rurais perante à Previdência oficial.

\section{RETERRITORIALIZAÇÃO DO NORDESTINO NA AMAZÔNIA}

A luta dos migrantes foi árdua não somente pelo trabalho que se constituía como um desafio que escapava à lógica que os trabalhadores conheciam, mas que perpassam seu universo de conhecimento, isto porque a nova realidade colocava-os diante da natureza complexa e exuberante na Amazônia, do imaginário construído e que induzia a saída da situação de penúria do nordeste para desfrutar de uma vida mais digna em outra região.

Medeiros Filho e Souza, citado por Nascimento Silva (2000, p. 45) constata que nos anos de 1877-1879, alguns proprietários de seringais viajavam ao Ceará, em busca de mão-de-obra para os seringais, aliciando trabalhadores e prometendo-lhes boas quantias e, ao chegarem às cidades de Manaus e de Belém, eram encaminhados para os seringais.

$\mathrm{Na}$ maioria das vezes, tais promessas jamais foram cumpridas, devido a uma série de obstáculos, tais como: dificuldades de transporte e alojamento, que somadas às enormes distâncias existentes entre as cidades e os seringais, as adversidades- feras selvagens, doenças tropicais, conflitos com os indígenas - e a exigência dos seringalistas quanto aos resultados de produção e consequentemente do auferimento de lucros, resultava num quadro perverso em que os seringueiros podem ser qualificados como vivendo em regime de escravidão.

Com todas essas dificuldades, o contingente de migrantes para Amazônia foi significativo, pois Benchimol (1999) argumenta que no período entre 1877 e 1878, deslocaram-se para a Amazônia cerca de 19.910 retirantes. No entanto, de 1877 a 1920 o total de imigrantes nordestinos já chegava a 300.000. A estimativa era que, desde o início do ciclo da borracha até os anos sessenta, aproximadamente 500.000 nordestinos vieram tentar a vida na região. 
O interesse mundial pela borracha, os esforços do governo norte-americano e brasileiro, o imaginário criado em torno do látex, de fato não configuraram tal atividade como de alto poder lucrativo, dado às peculiaridades da região, além disso, havia o despreparo técnico da força de trabalho empregada na atividade extrativa.

Essa relação é mais profunda porque se tratava de re-arranjos ou reconfiguração da economia de escala em nível internacional, nas quais a competição prima pela eficiência e eficácia, o que no caso brasileiro estava suplantada pelas técnicas adotadas.

A suplantação conecta-se aos aspectos de que enquanto a extração da Hevea brasiliensis era colhida in natura, demandando um "exército" para a obtenção de uma produção quase artesanal, em contrapartida havia uma produção em escala com plantas geneticamente melhoradas por parte dos asiáticos que conseguiam melhor produtividade a partir das plantas pirateadas da Floresta Amazônica.

Assim, a atividade extrativista da Hevea brasiliensis na Amazônia estava superada no ponto de vista da competição do mercado internacional. Somente com o advento da II Guerra Mundial a atividade é retomada com grande expressividade, entretanto a sobrevida é extremamente curta e inicia-se um novo declínio que parece decretar definitivamente o fim da atividade extrativista na Amazônia, visto a inserção de novos componentes e significados econômicos, sociais, políticos e ambientais para a região. Uma nova realidade, perversa e antagônica se instala e os modos de vida se rompem de forma que se apresenta como definitiva.

O alto custo na implantação dos seringais decorreu de inúmeros fatores, tais como: a) a delonga temporal do mateiro ${ }^{9}$ em encontrar a localização das árvores produtoras de seringa; b) as grandes distâncias entre as árvores, em média de duas a três por hectare; c) a baixa produtividade das árvores e a baixa produção; d) o seringueiro se sujeita a percorrer grandes distâncias para extrair o látex; e) a acirrada competição internacional, enquanto na Ásia realizava-se o cultivo extensivo, tecnológico e comercial da seringa, no Brasil se praticava o extrativismo baseado naquilo que a natureza oferecia.

\footnotetext{
${ }^{9}$ Trabalhador que nos tempos dos seringais amazônico era responsável pela abertura de trilhas na floresta, hoje o termo está relacionado com o processo de reconhecimento de espécies florísticas, sendo importante para a realização das pesquisas, devido a seu grande conhecimento empírico.
} 
FIGURA 1 E 2 - CONSTITUIÇÃO E CONFIGURAÇÃO GEOGRÁFICA DE UM SERINGAL

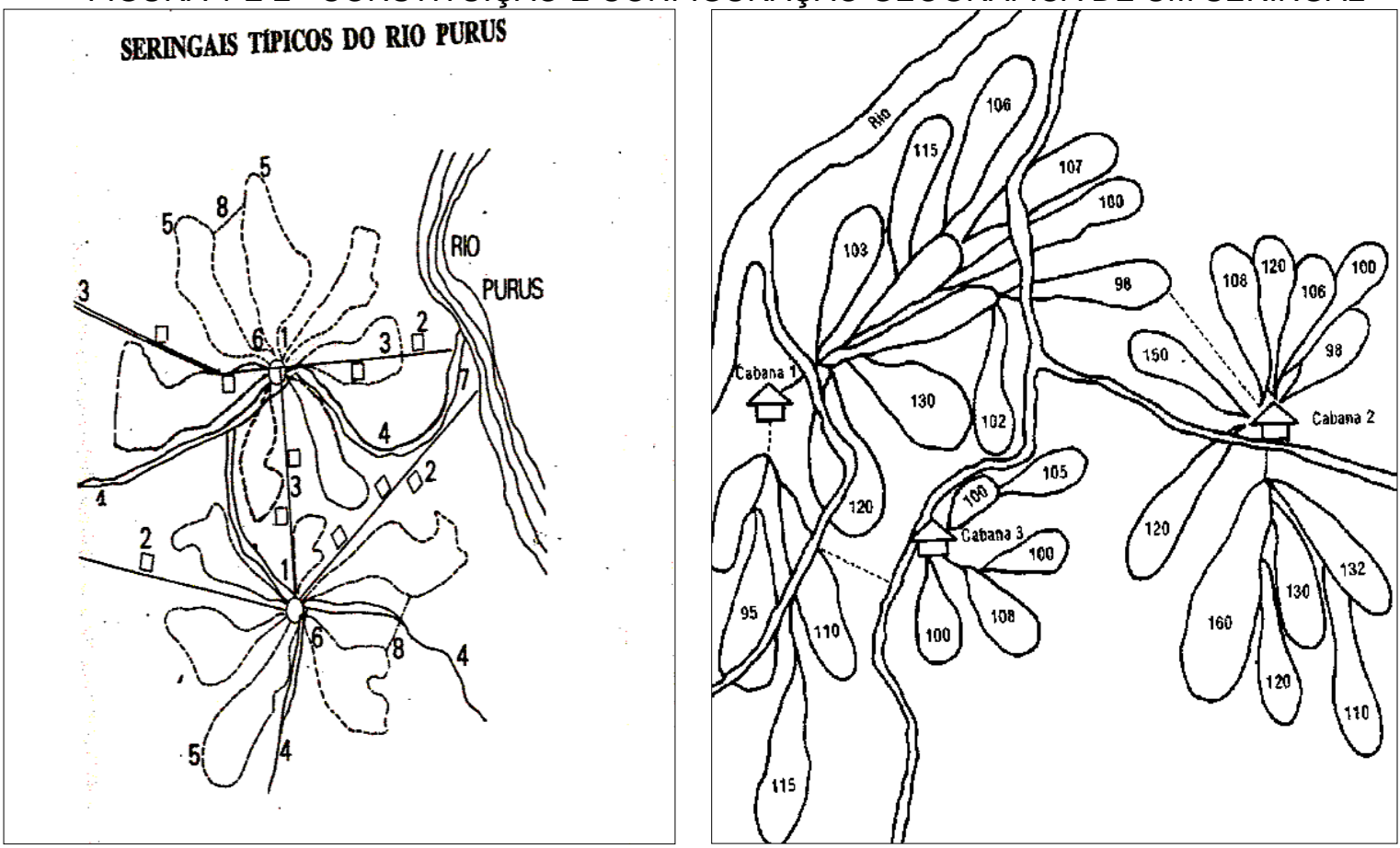

Fig. 01 - Croquis de Euclides da Cunha In: CUNHA, E. Um Paraíso Perdido.

Fig. 02 - Croquis de Sebastião Ferrarini. In: FERRARINI, S. A. Progresso e Desenvolvimento no Purus, 1976.

Figura 01: 1 - sede do seringal; 2 - barracos ou casas dos seringueiros; 3 - varadoro (estradas); 4 igarapé; 5 - volta da estrada; 6 - boca da estrada; 7 - barracão; 8 - caminho ligando estradas. Figura 02: Os números referem-se a quantidade de seringueiras existentes em cada uma das estradas.

$\mathrm{Na}$ lógica de produção do seringal, a cada seringueiro era confiado o direito e a responsabilidade de cortar duas ou três estradas de seringas, conforme figuras acima, cada uma dessas estradas possuíam em média cem árvores, exploradas em dias alternados para não exaurir sua capacidade produtora.

A exploração se dava preferencialmente no período de pluviosidade baixa, aproximadamente seis meses de trabalho muito intenso. A inexperiência, a falta de cuidados no momento das incisões e a exploração durante vários anos, fez com que se desenvolvessem troncos nodosos e quase impenetráveis, levando a seringueira a produzir cada vez menos látex, tornando elevado o custo para manter os seringueiros nas colocações.

Utilizando-se dessa situação, os seringalistas conservavam um regime extremamente intransigente sobre os trabalhadores, os quais só alcançavam o "direito" de exploração dos seringais após adquirirem os adiantamentos com 
mantimentos $^{10}$ estritamente por intermédio de seus patrões, ${ }^{11}$ além do comprometimento de entrega de toda a produção, exclusivamente, ao patrão que lhe ofereceu o aviamento.

O modelo de administração dos seringais se configurava como uma terrível e impiedosa exploração da força de trabalho do seringueiro. Além disso, os mantimentos eram vendidos e só contabilizados no final do ano a preços vigentes. Toda a produção desses trabalhadores era contabilizada pelo preço que a borracha tinha alcançado no mês de janeiro do ano de sua exploração. Essa forma de gerenciamento ficou conhecida como sistema de barracão.

Os investimentos destinados à extração do látex na Amazônia propiciaram uma mobilidade demográfica acentuada em praticamente toda a região, instituindo uma nova ressignificação cultural. O aumento demográfico possibilitou, no imaginário, o aspecto de grandiosidade, inspirada pelos ideais da modernidade que incentivavam cidades como Manaus e Belém que erguessem monumentos, palacetes e obras que expressassem a suntuosidade apoiada na visão modernista da alta sociedade (elite política e econômica), que enriquecida pela exploração gomífera reivindicasse e construísse templos culturais como os Teatros Amazonas e o da Paz, afim de desfrutar culturalmente os beneplácitos que se operacionalizavam principalmente no mundo desenvolvido (leia-se Europa) ${ }^{12}$.

De outra forma, a interação dos bravos "soldados" com a floresta criou-se uma relação dialética entre homem e natureza, uma vez que a natureza proporcionava tudo o que seringueiro necessitava para seu sustento, procurando explorá-la de forma sustentável.

\footnotetext{
${ }^{10}$ Produtos do tipo: fumo, querosene, munição, sal, açúcar, café, aguardente, dentre outros utensílios necessários à sua manutenção durante a permanência nos seringal.

${ }^{11}$ Modo como eram conhecidos e tratados os donos dos seringais amazônicos.

${ }^{12}$ Um bom exemplo desta constatação pode ser compartilhada em Fitzcarraldo (1982), um filme épico de Werner Herzog, que retrata a opulência dos seringalistas e a perspectiva de se realizar a cultura européia nos trópicos amazônicos. Assim, não tem como se negar a construção de monumentos como forma de expressão artístico-cultural, mesmo que estas não retratem o modo de vida cabocla e indígena, aliás essas representações de vida local são as que possuem menor ou quase nenhuma visibilidade, ou seja o culto que se faz está relacionada às representações de exogênia, como processo de "apagamento" e negação da memória local, isto porque dentro da concepção dos vencedores só pode ser revelado aquilo que está diretamente relacionado àqueles que são vencedores, seja político, simbólico ou economicamente como construtores da história. Isso nos lembra uma célebre frase sartreniana: "o inferno e os demônios são os outros", enquanto nós somos os heróis.
} 
A reterritorialização do nordestino na Amazônia foi construída mediante essa árdua luta frente às adversidades encontradas na selva, gerando uma dialética e significativa desse homem com a natureza, como nos lembra Amaral (2004, p.88):

\begin{abstract}
Integra-se no universo de seu espaço vivido. Existindo uma reciprocidade no seio da comunidade e a intimidade com o meio onde ele caça, retira o sustento da família, a "mata" é "valor", é vida. É o lugar do perigo, mas ao mesmo tempo, é um lugar que representa a liberdade. A relação desenvolvida entre a floresta e o seringueiro é tão íntima que ela torna-se um pouco de si, a extensão física de seu corpo.

Os seringueiros desenvolveram sua própria lógica de racionalidade com relação à floresta [...]. Para o seringueiro a "mata" é um espaço de moral, é o local onde se movimenta, é o espaço de produzir e viver. A floresta é ao mesmo tempo onde ele nasce, onde ele produz e onde ele é enterrado. A "mata é o lugar de vida". ( $\mathrm{sic}$.
\end{abstract}

Apesar da adversidade do meio ambiente, o seringueiro expressa um sentimento de afetividade com a floresta em razão de proporcionar sua subsistência. Para ilustrar tal sentimento, apresentamos a canção do seringueiro Claudino Soares ${ }^{13}$, em que revela a relação representativa do seringal, como parte de sua vida:

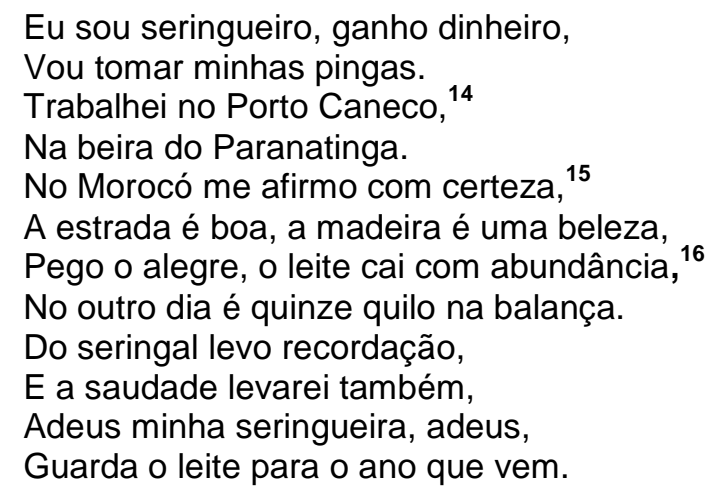

Essa canção com sua simplicidade e beleza retrata a despedida do seringueiro, a fonte de vida, que diante do sofrimento e da solidão encontra na extração do látex

\footnotetext{
${ }^{13}$ Entrevista concedida ao pesquisador Antônio Carlos Galvão da Silva da Universidade Federal de Rondônia, como suporte à pesquisa sobre os seringais da Amazônia.

${ }^{14}$ Nome do seringal situado às margens do Rio Teles Pires no Estado do Mato Grosso.

${ }^{15}$ Igarapé chamado de Morocó, em Mato Grosso.

${ }^{16}$ A relação do seringueiro até mesmo com suas ferramentas de trabalho era tão intensa que este se referia à faca de cortar seringa com sendo alegre.
} 
a esperança na árvore para tirar seu sustento, e incorpora na sua alma a lembrança e a profunda saudade dos tempos idos.

\section{CONCLUSÃO}

A análise que fazemos sobre o processo de des(re)territorialização de uma importante parcela da população nordestina, forçada a migrar, a deixar a sua terra de origem, em busca de melhores condições de vida, resultando numa adaptação a um novo modo de vida na Amazônia.

No nosso entendimento analítico, o processo de des(re)territorialização com seus aspectos políticos, sociais e econômicos foram importantes para as (re)configurações do território amazônico. Entretanto, é a variável cultural que possibilitou a construção de modos de vida específicos, como se observa entre os ribeirinhos, coletores de castanhas e pescadores através de suas relações com 0 espaço e o meio ambiente.

Essa adaptação do modo de vida, propiciada através do processo de des(re)territorialização, possibilitou a configuração de uma cultura, mesclada com a local, de modo que se revela como um importante contribuinte na (re)configuação e afeição do território amazônico e que, ainda, necessita ser melhor interpretada tanto na academia quanto na sociedade. E, sobretudo, pelo poder público.

Essa admoestação é pertinente porque os seringueiros foram importantes atores que contribuíram intensa e diretamente para assegurar a territorialidade. Ou seja, com seu árduo trabalho tornaram-se responsáveis pela configuração territorial brasileira, particularmente destacando a conquista do atual Estado do Acre, através da luta, além do incremento populacional da Amazônia.

Não se pode esquecer que a territorialização foi marcada por inúmeros conflitos inter-étnicos em que seringueiros e, especialmente, os indígenas se tornaram as grandes vítimas provocadas pela inserção, força e expansão do capitalismo. Como conseqüência dessa estratégia de territorialização, gerou-se uma população empobrecida e socialmente excluída da grande riqueza produzida pela borracha. 
Ao mesmo tempo, nesse espaço de "produzir e viver", muitos seringueiros, após terem assegurado os interesses do Governo Federal e do capital internacional, foram esquecidos e abandonados, não somente nos longínquos seringais, como nas periferias das cidades amazônicas. Não conseguiram mais sobreviver da extração de seringa, devido aos baixos preços, passaram a ser expulsos da terra e a sorte de novas formas de produção do espaço e inseridas na região após a década de 1960.

Enfim, novamente reterritorializando-os, mas registrando os seus infortúnios em relação ao descaso manifestado pelo Governo Federal. Podemos notar como exemplo disso o relato do soldado da borracha Claudino Soares:

[...] nós era para ter outro valor [...] felizmente a gente é brasileiro e tem orgulho de ser brasileiro, mas um orgulho com sentimento, o senhor entendeu? Um orgulho com sentimento, por que o sofrimento nosso foi demais, acabava a roupa, tinha que amarar estopa na cintura para poder cortar borracha, procurar borracha [...].

Diante dos esforços destinados à atividade de extração do látex na Amazônia e de toda dedicação e vidas doadas nessa árdua guerra, os seringueiros não lograram os frutos que mereciam. Todavia, inevitavelmente temos que reconhecer que tais fatos foram os grandes responsáveis pela atual configuração territorial da Amazônia.

\section{REFERÊNCIAS}

ALMEIDA SILVA, Adnilson de. Impactos Socioculturais em Populações Indígenas de Rondônia: Estudo da Nação Jupaú. Dissertação de Mestrado. Porto Velho: UNIR, 2007.

AMARAL, J.J.O. Mata Virgem: Terra Prostituta. São Paulo: Terceira Margem, 2004.

ANDRADE, M.C. Geopolítica do Brasil. Campinas: Papirus Editora, 2001.

BENCHIMOL, S. Romanceiro da Batalha da Borracha. Manaus: Imprensa Oficial, 1992.

Amazônia: Formação Social e Cultural. Manaus: Valer, 1999.

COSTA, R.H. O Mito da Desterritorialização: Do "Fim dos Territórios" à Multiterritorialidade. Rio de Janeiro: Bertrand Brasil, 2004. 
Concepções de Território para Entender a Desterritorialização. In: Santos, M. et al. Território, Territórios: Ensaios Sobre o Ordenamento Territorial. $2^{\mathrm{a}}$ ed. Rio de Janeiro: DP\&A, 2006.

CUNHA, E. À Margem da História. São Paulo: Martins Fontes, 1999.

. Um paraíso perdido. Col. Brasil 500 anos. Brasília: Senado Federal, 2000.

DEAN, W. A Luta Pela Borracha no Brasil. São Paulo: Nobel, 1989.

FERRARINI, S.A. Transertanismo: Sofrimento e Miséria do Nordestino na Amazônia. Petrópolis: Vozes, 1979.

Progresso e desenvolvimento no Purus. São Paulo: FTD, 1976.

GALLOIS, D. Terras ocupadas? Territórios? Territorialidade? In: RICARDO, F. Terras Indígenas \& Unidade de Conservação da Natureza: o desafio da sobreposição. São Paulo: Instituto Socioambiental, 2004.

LEONEL, M. Etnodicéia Uruéu-au-au: o endocolonialismo e os índios no Centro de Rondônia, $O$ direito à diferença e à preservação ambiental. São Paulo: EDUSP/IAMA/FAPESP, 1995.

NASCIMENTO E SILVA, M.G.S. O Espaço Ribeirinho. São Paulo: Terceira Margem, 2000.

OLIVEIRA, A.U. Integrar para não entregar: políticas públicas e Amazônia. 2ª̣. ed. Campinas: Papirus, 1991.

PAULA, J.M. KARO e IKÓLÓÉHJ: escola e seus modos de vida. Dissertação de Mestrado. Porto Velho: UNIR, 2008.

RIBEIRO, B.G. O índio na cultura brasileira. 3ª ed. Rio de Janeiro: Revan, 2000.

SANTOS, M. A Natureza do Espaço: Técnica e Tempo, Razão e Emoção. 4⿳亠丷a ed. São Paulo: EDUSP, 2006.

SILVA, A.C.G. O seringal no município de Lábrea: o espaço vivido e a resistência de um tempo. Dissertação de Mestrado. Porto Velho: UNIR, 2008.

SILVA, J.C. CUNIÃ: Mito e Lugar. Dissertação de Mestrado (Mimeog). São Paulo: FFLCH/USP, 1994.

VILAÇA, A.M.N. Quem Somos Nós: os Wari encontram os brancos. Rio de Janeiro: EDUFRJ, 2006.

(Recebido em dezembro/2008. Aceito em Janeiro/2010) 